\title{
ISSN 1414-6509 \\ POLO NAVAL E OFFSHORE DO RIO GRANDE: DESAFIOS COLOCADOS AO COREDE SUL ${ }^{1}$
}

\author{
Andréa Bento Carvalho \\ Professora Assistente da FURG. Doutoranda em Economia do Desenvolvimento da PUCRS. \\ Endereço para contato: FURG, ICEAC. Rua Glicério P. de Carvalho, $n^{\circ} 81$ - Coxilha - Santa Vitória do \\ Palmar, RS - Brasil. \\ CEP: 96230-000 E-mail: andreab.carvalho@yahoo.com.br

\section{Gustavo Inácio de Moraes} \\ Professor da Pontifícia Universidade Católica do Rio Grande do Sul - PUCRS. \\ Endereço para contato: PUCRS, Escola de Negócios. Avenida Ipiranga, ${ }^{\circ} 6681$, prédio 50, $10^{\circ}$ andar, sala \\ 1001-11. Partenon - Porto Alegre, RS - Brasil. \\ CEP: 90619-900 E-mail:gustavo.moraes@ pucrs.br
}

\section{Paulo Henrique de Oliveira Hoeckel}

Doutorando em Economia do Desenvolvimento (PPGE/PUCRS).

Endereço para contato: PUCRS, Programa de Pós-Graduação em Economia. Avenida Ipiranga, nº 6681, prédio $50,11^{\circ}$ andar - Partenon - Porto Alegre, RS - Brasil.

CEP: 90619-900 E-mail:ph.hoeckel@gmail.com

Recebido em 03 de novembro de 2016. Aceito em 13 de março de 2017.

\section{RESUMO}

Este artigo tem por objetivos identificar empresas fornecedoras à indústria do petróleo, gás natural e naval localizadas no Rio Grande do Sul e, em particular, na região do COREDE Sul, inseridas na Rede Petro/RS e SEBRAE, além de realizar uma breve análise comparativa do grau de concentração das atividades econômicas entre os oito COREDES com maior número de empregados. Neste sentido, conferindo atenção especial ao COREDE Sul observando se, ao longo dos anos, ocorreram alterações no grau de concentração de suas atividades em função da operação do Polo Naval e Offshore. Para obtenção dos índices de concentração foi adotada a metodologia do índice Hirschman-Herfindahl $(\mathrm{HH})$, com dados de emprego apurados junto a RAIS. Os resultados deste trabalho evidenciam a tendência de os COREDES Metropolitano, Vale do Rio dos Sinos e Serra se consolidarem como principais fornecedores ao Polo Naval e Offshore do Rio Grande, e o COREDE Sul participando da referida cadeia com uma pequena quantidade de empresas, muitas delas prestadoras de serviços de baixo valor agregado. As evidências ainda apontam que as atividades do Polo Naval e Offshore do Rio Grande tendem a aprofundar uma característica já predominante no COREDE Sul, a desconcentração.

PALAVRAS-CHAVE: Indústria Naval, Desenvolvimento Regional, Índice HH.

1 Artigo elaborado com apoio do projeto AUXPE 3166/2013 Edital 55 - Pró-Integração (CAPES/MI). 


\begin{abstract}
This article aims to identify suppliers to the oil industry, natural gas and naval located in Rio Grande do Sul and, in particular, in the COREDE South, inserted the Rede Petro/RS and SEBRAE, and perform a brief comparative analysis the degree of concentration of economic activities among the eight COREDES with more employees. In this regard, special attention to South COREDE observing, over the years, there were changes in the degree of concentration of its activities due to the operation of the Polo Naval and Offshore. To obtain the concentration indices was adopted the methodology of the Hirschman-Herfindahl index $(\mathrm{HH})$, calculated with employment data from the RAIS. The results of this work show the tendency of COREDES Metropolitano, Vale do Rio dos Sinos and Serra are consolidated as major suppliers to the Polo Naval and Offshore Rio Grande, and the South COREDE participating in said chain with a small number of companies, many of them providers of low value-added services. The evidence also reveal that the activities of the Polo Naval and Offshore Rio Grande tend to deepen an already predominant feature in COREDE South, desconcentration.
\end{abstract}

KEY WORDS: Shipbuilding, Regional Development, HH Index.

\title{
1. INTRODUÇÃO
}

A indústria naval brasileira encontra-se em fase de retomada de suas atividades, que_é evidenciada a partir da modernização e ampliação dos estaleiros antigos, situados no estado do Rio de Janeiro, e com a construção de novos estaleiros em vários Estados brasileiros, como Pernambuco e Rio Grande do Sul, para citar os maiores, bem como também no Rio de Janeiro, no Porto de Itaguaí.

Desde 1930 o país vive momentos muito pontuais de expansão seguidos de períodos de retração da construção naval. Ao longo dos governos brasileiros, a indústria da construção naval sempre recebeu incentivos. O marco de sua criação ocorreu no governo de Juscelino Kubistschek (1956 - 1961), assim como uma serie de medidas visando seu desenvolvimento.

No governo Costa e Silva (1967 a 1969), mais um conjunto de políticas voltadas ao setor de construção naval foi implantado, fazendo com que neste período o setor atinja o status de segundo maior do mundo. No entanto, na década de 80, o Brasil enfrenta uma grande crise econômica, e a fim de evitar que os desequilíbrios econômicos atingissem a indústria naval, o governo brasileiro propõe novas interferências no setor naval, implantando o Plano Permanente de Construção Naval (PPCN), que vigorou entre os anos de 1981 a 1983 (SINAVAL, 2010).

Porém, o que se observou no transcorrer desta década foi o agravamento da crise nacional e internacional, onde os subsídios e financiamentos, extremamente necessários ao setor naval brasileiro, foram diminuindo até a sua quase total extinção. Países estrangeiros passaram a restringir a utilização de navios de países em desenvolvimento. Com esta trajetória, no final dos anos 80 a indústria da construção naval brasileira 
contava com apenas dois mil empregados, cerca de vinte vezes menos do que na época do seu auge (MDIC, 2002).

A década seguinte (anos 90) foi marcada pela liberalização do transporte marítimo de longo curso no Brasil. Logo, os armadores que já estavam extremamente fragilizados tornam-se ainda mais vulneráveis com a entrada da concorrência internacional. Assim, o cenário que se consolida na indústria naval brasileira é a descapitalização, a perda de eficiência e a já citada ausência de encomendas aos estaleiros nacionais. As empresas fornecedoras da indústria naval também são diretamente impactadas e tiveram importantes segmentos extintos.

Em 1997, no governo Fernando Henrique Cardoso, foi criada a Lei 9.478, conhecida como a Lei do Petróleo, abrindo o mercado brasileiro de exploração e refino do petróleo a novos operadores. Neste mesmo ano, como tentativa de reverter a condição de estagnação em que se encontrava, o Governo Federal, através do Ministério da Indústria do Comércio e do Turismo, define duas grandes linhas estratégicas, especificamente direcionadas ao setor de construção naval brasileira, que segundo Domingues et al., (2008), são: recuperação e estímulo ao mercado interno de navios e implantação de um programa de exportação de navios. Porém, segundo os autores, estas estratégias enfrentariam obstáculos importantes à sua prática, uma vez que: - os armadores nacionais apresentavam um alto grau de endividamento, - os estaleiros, após anos de letargia, não tinham um nível tecnológico compatível com as necessidades do setor; bem como atrasos nos repasses do Fundo de Marinha Mercante, aspectos fundamentais ao financiamento da indústria naval nacional. Estes fatos se traduziram em uma total falta de encomendas de novos navios.

Ainda segundo Domingues et al. (2008), no processo das eleições presidenciais de 2002 o setor naval brasileiro ganhou novo enfoque devido a encomenda de duas plataformas offshore pela PETROBRAS junto a estaleiros de Singapura. Este fato culminou nas opiniões do então Presidente da República, Fernando Henrique Cardoso, afirmando que a importação das plataformas era uma questão econômica e que o país não aportava o padrão tecnológico exigido para a construção das mesmas, e do candidato à Presidência da República, Luiz Inácio Lula da Silva, pregando a importância estratégica para o país da fabricação das plataformas.

Eleito presidente, Luiz Inácio Lula da Silva decide tomar como política de seu governo a recuperação da indústria naval brasileira. Os principais pontos motivadores para a decisão do Governo Federal estimular a indústria naval nacional foram os altos custos com o afretamento por parte da PETROBRAS, a renovação da frota da TRANSPETRO (PETROBRAS Transportes S.A), a descoberta de campos em águas profundas, o que demandaria maior quantidade de embarcações de apoio e plataformas, e mudanças na política de conteúdo local nas rodadas de licitação da Agência Nacional de Petróleo (ANP). Com esta evolução, retrata-se o ano de 2003 como significativo para a indústria naval direcionada ao petróleo e gás. 
Ainda no ano de 2003 a PETROBRAS propõe uma nova política de compras, reservando aos estaleiros locais a preferência nas encomendas de navios e equipamentos para a exploração e produção de petróleo, sendo estabelecido um índice de nacionalização para suas demandas.

Um dos destaques desta nova política, e também considerado o alicerce da retomada da indústria naval, foi o Programa de Modernização da Frota (Promef), lançado em 2005 pela TRANSPETRO, uma empresa subsidiária da PETROBRAS. O programa determina que todos os navios sejam construídos obrigatoriamente no Brasil, com índices de nacionalização estipulados a priori. (TRANSPETRO, 2010).

Com o tamanho das encomendas geradas pela TRANSPETRO, aliada às novas demandas da PETROBRAS, muito em função das descobertas do pré-sal e seu grande horizonte de exploração e produção de petróleo e gás natural, a dinamização da indústria naval brasileira é consolidada em definitivo no país.

Para atender a todos os novos cenários estabelecidos no setor da construção naval voltada ao petróleo e gás, no ano de 2003 o governo federal entende como necessária a ampliação, atualização e construção de novos estaleiros, já que a capacidade instalada até aquele momento não fazia frente às novas demandas. Assim, é proposto pelo então governo um novo arranjo locacional dos estaleiros ao longo da costa brasileira.

Neste contexto, o Governo Federal, considerando as dimensões físicas e o interesse em desconcentrar espacialmente o parque naval brasileiro concentrado no estado do Rio de Janeiro, aponta os portos do Rio Grande, no Rio Grande do Sul, e de Suape, em Pernambuco, como alternativas para sediarem polos navais mais modernos em termos tecnológicos. Os estados de Santa Catarina, Espírito Santo, Paraná, Bahia e São Paulo também são apontados como opções locacionais nesta nova fase da indústria naval (DOMINGUES, et al., 2008).

Ao promover a referida desconcentração espacial na indústria naval brasileira, o Governo Federal transforma em política de Estado a política de Governo promulgada anteriormente, visto a intenção em, por exemplo, fomentar o desenvolvimento industrial e a inovação tecnológica nestas novas regiões sedes. Este novo arranjo espacial impõe desafios, e para ajudar na superação destes, o Programa de Mobilização da Indústria de Petróleo e Gás Natural (PROMINP) é criado. De acordo com Silva (2006), o PROMINP foi lançado pelo Presidente da República Luiz Inácio Lula da Silva em 2003, com intuito de fazer da produção de petróleo e gás natural, transporte marítimo e dutoviário, oportunidades de crescimento para a indústria nacional de bens e serviços.

Desta forma, o Porto do Rio Grande foi escolhido para sediar um dos polos navais mais modernos do país em termos tecnológicos. Inserido em uma estratégia de desenvolvimento regional, o estabelecimento do citado polo naval pode ser enquadrado em uma política chamada Top Down, ou "de cima para baixo", tendo esta estratégia como característica a indução por políticas públicas, ou seja, uma estratégia de governo em que o território serve de receptor. Contudo, este pode se engajar ao processo que está sendo 
implantado através das janelas de oportunidades que advêm destas implantações políticas.

Neste caso, pode-se considerar a inserção de fornecedores locais nesta cadeia da indústria naval como uma janela de oportunidade, levando em conta, por exemplo, a excelência do estado do Rio Grande do Sul no segmento metalmecânico e eletroeletrônico.

Já nesta primeira década do século XXI, os novos cenários na exploração de petróleo e gás natural offshore estão dinamizando a recuperação e também aumentando a participação de fornecedores ligados em toda esta cadeia produtiva da indústria naval. Especificamente para o estado do Rio Grande do Sul, além do estímulo à cadeia produtiva da indústria naval, estão sendo propostos três tipos de projetos, projetando desenvolvimento dos segmentos produtivos da petroquímica, do refino e de dutos. Neste sentido, as empresas gaúchas têm a possibilidade não apenas de fornecerem para a indústria naval, mas também tornarem-se fornecedoras ou ainda aumentarem a participação no fornecimento à Refinaria Alberto Pasqualini (REFAP), que segundo Oliveira et al., (2010), é a maior empresa de energia do Rio Grande do Sul e a segunda maior empresa no setor de petroquímica e química do Brasil.

A partir da estruturação do polo naval do Rio Grande, dos atuais projetos nas áreas de petróleo, gás e naval para o Rio Grande do Sul e da intenção da Federação das Indústrias do Estado do Rio Grande do Sul (FIERGS) de elevar o patamar de participação das empresas gaúchas no fornecimento para a PETROBRAS dos atuais 1,2 \% para 10\% em cinco anos (ZERO HORA 2010), é estabelecido, de imediato, um desafio ao COREDE Sul (Conselho Regional de Desenvolvimento da Região Sul) ${ }^{2}$, sede do polo naval, e aos demais COREDES do Estado, potenciais fornecedores de bens e serviços a essa nova cadeia produtiva em implantação no Estado, de fortificarem sua organização diante das demandas industriais efetivas e projetadas, de forma a consolidar de forma sustentada o processo de desenvolvimento da indústria no Rio Grande do Sul. Em essência, o desafio ressaltado aqui é inserir uma rede de fornecedores, localizados estes no COREDE Sul, para que os mesmos atendam à nova cadeia produtiva em processo de instalação.

Nos atentando ao COREDE Sul, podemos dizer que por ora há configuração de um $2^{\circ}$ ciclo de desenvolvimento exógeno no município do Rio Grande, induzido pelo polo naval, colocando de imediato o problema da inserção de atores locais na cadeia de supridores deste novo segmento produtivo. Assim, a questão que se coloca refere-se a saber se está havendo mobilização dos agentes dos segmentos industriais da metalmecânica, química e eletroeletrônica, dentre outras, baseadas no Rio Grande do Sul

2 Os COREDES são regionalizações adotadas pelo Estado Rio Grande do Sul a partir do ano de 1994, e atuam como fórum de discussão e decisão a respeito de políticas e ações que visam o desenvolvimento regional. Atualmente o Estado possui vinte e oito COREDES (SEPLAG, 2011). 
e, em especial no COREDE Sul, para se tornarem fornecedores de insumos, produtos e serviços para essa nova cadeia produtiva.

Tal problemática é relevante considerando que o Rio Grande do Sul tem capacidade industrial para aprofundar a sua inserção nesta cadeia de suprimentos demandados. O problema está em que estes fornecedores encontram-se espacialmente concentrados na Região Metropolitana de Porto Alegre, na Serra e no Planalto. Daí a necessidade de se analisar a capacidade de resposta da indústria, baseada na região do COREDE Sul, sede do Polo Naval e Offshore.

É sabido, também, que a introdução de novos segmentos produtivos em uma determinada região, especialmente aquelas definidas como indústrias industrializantes ou motrizes, tendem a gerar grandes impactos socioeconômicos, muitas vezes excludentes aos atores locais, devido às escalas de produção e aos níveis de conteúdo tecnológico inerente a grandes projetos industriais.

Com isso, este trabalho tem como objetivos: i) identificar empresas fornecedoras à IPG\&N localizadas no Rio Grande do Sul e, em particular, na região do COREDE Sul, inseridas na Rede Petro/RS e SEBRAE (Serviço de Apoio às Micro e Pequenas Empresas), a fim de analisar em que dimensão estas empresas fornecedoras à IPG\&N estão constituídas dentro do COREDE Sul; ii) realizar uma breve análise comparativa do grau de concentração das atividades econômicas entre os oito COREDES com maior número de empregados. Para tanto, utilizou-se do índice de concentração HirschmanHerfindahl (HH). Neste sentido, deu-se atenção especial ao COREDE Sul observando se, ao longo dos anos, ocorreram alterações no grau de concentração de suas atividades em função da operação do Polo Naval e Offshore. Com vistas a alcançar os objetivos propostos e tentar responder a questão formulada, fez-se uso do estudo de caso $^{3}$, já que está focado na investigação do Polo Naval e Offshore do Rio Grande. Desta forma, a fim de identificar as empresas, foram realizados levantamentos indiretos junto à Rede Petro/RS ${ }^{4}$ e SEBRAE/RS ${ }^{5}$ referentes aos segmentos industriais que compõem a referida rede de fornecedores de insumos, produtos e serviços. Após o levantamento total das empresas fornecedoras de insumos, produtos e serviços, foi feita a tipificação das

3 Segundo Ventura apud Gil (2007), o estudo de caso é uma metodologia ou uma escolha de um objeto definido pelo interesse em casos individuais.

4 A Rede Petro foi criada através do convênio entre PETROBRAS e SEBRAE, constituindo-se de um conglomerado formado por 18 redes atuantes em regiões específicas do país, representando empresas fornecedoras de bens e serviços à indústria de petróleo, gás natural e energia. No Rio Grande do Sul a Rede Petro tem como objetivos: o desenvolvimento de tecnologia adequada ao setor, ampliar o mercado para empresas gaúchas, qualificação de recursos humanos, possibilitando assim o acesso dos trabalhadores ao mercado e atendimento das demandas; aproximar a iniciativa privada dos centros de pesquisa gaúchos (REDE PETRO/RS, 2010).

5 O SEBRAE é composto por 27 unidades descentralizadas, sendo uma em cada estado do Brasil e Distrito Federal, visando promover a competitividade e o desenvolvimento dos pequenos negócios. O SEBRAE/RS atua em parceria com a Rede Petro e PETROBRAS no desenvolvimento do Projeto Adensamento da Cadeia Produtiva do Petróleo, Gás e Energia, com a finalidade de promover a inserção das micro e pequenas empresas neste mercado, objetivando adequar à base de fornecedores ao que os investidores necessitam, e estimular processos locais de desenvolvimento (SEBRAE, 2010). 
mesmas, através da consulta ao catálogo FIERGS, bem como os sítios eletrônicos, quando disponíveis.

O presente trabalho está estruturado da seguinte forma: além desta seção introdutória, a segunda seção aborda o novo ciclo de crescimento econômico que ocorre a partir do município do Rio Grande, processo exógeno induzido pelo Estado Brasileiro e grandes corporações nacionais e estrangeiras. Na terceira seção, é analisada brevemente a política de conteúdo local proposta pela PETROBRAS e Agência Nacional do Petróleo, bem como destacado o primeiro desenho locacional no que se refere à potencial cadeia de fornecedores a IPG\&N no Rio Grande do Sul, apresentando as cadeias de suprimento dos COREDES Metropolitano, Vale do Rio dos Sinos, Serra, Noroeste Colonial, Vale do Rio Pardo, Alto Jacuí, Norte, Central, Jacuí Centro, Produção e Fronteira Noroeste, que começam a se estruturar para atender as demandas geradas pela reserva de conteúdo nacional e pela falta de capacidade produtiva que os fornecedores já estabelecidos na região Sudeste tem em atender esta vultosa demanda. A quarta seção apresenta a mobilização empresarial do COREDE Sul, sede do polo naval e offshore do Rio Grande, frente às grandes demandas geradas pelo referido empreendimento, bem como as características particulares referentes ao polo naval do Rio Grande em relação à cadeia de suprimentos. A quinta seção, aborda os índices de concentração Hirschman-Herfindahl (HH) calculados para os oito COREDES com maior número de empregados a fim de apontar qual o nível de concentração das atividades econômicas dos mesmos, observando se, ao longo dos anos, ocorreram alterações no grau de concentração das atividades pela operação do Polo Naval e Offshore no COREDE Sul, sede do referido empreendimento. Por fim, na sexta e última seção, são elaboradas as considerações finais do presente artigo.

\section{A ESTRATÉGIA DE DESENVOLVIMENTO REGIONAL ATRAVÉS DA DINAMIZAÇÃO DA INDÚSTRIA NAVAL NO SÉCULO XXI: O CASO DO POLO NAVAL DO RIO GRANDE}

O COREDE Sul e, em especial o município do Rio Grande, vivem momentos de transformações com a introdução de novas práticas produtivas, econômicas e culturais. Estas novas práticas advêm da implantação da indústria naval no município, que, assim como implementados em outros municípios no país, vem marcando o que podemos chamar da dinamização da indústria naval no Brasil. Esta dinâmica aparece como consequência da desconcentração espacial dos estaleiros, promovido pelo Governo Federal a partir do ano de 2003.

Segundo Domingues et al., (2008), no ano de 2005 dois projetos de estaleiros foram apresentados para o Porto do Rio Grande, sendo eles o estaleiro AKER-PROMAR e o estaleiro Rio Grande. O estaleiro AKER-PROMAR concentra seu interesse na construção de grandes navios como os da classe SUEZMAX e AFRAMAX, e nos de menor porte da classe PANAMAX. Já o estaleiro Rio Grande volta sua proposta à 
reparação naval e construção de navios para a TRANSPETRO. Contudo, as descobertas de óleo e gás natural em águas profundas, o chamado pré-sal, modificam os investimentos da PETROBRAS, levando a estatal a reformular seus planos, decretando a construção do primeiro dique seco da América Latina para reparo e construção de plataformas offshore. A licitação para a construção deste dique seco foi vencida em 2006 pelo estaleiro Rio Grande, capitaneado pelo grupo WTorre de São Paulo.

O dique seco construído em Rio Grande iniciou com dimensão de 130 metros de largura por 140 metros de extensão e profundidade de 14 metros. De acordo com Domingues et al., (2008), com este novo rumo de investimento dado pela PETROBRAS, o então Polo Naval do Rio Grande passa a ser Polo Naval Offshore do Rio Grande. A diferença consiste em no primeiro a finalidade era a reparação e/ou construção de navios, enquanto no modelo atual, do Polo Naval Offshore do Rio Grande, este abrange a construção e/ou reparação de plataformas e navios de apoio marítimo para atividades offshore da indústria de petróleo e gás (DOMINGUES et al., 2008).

O primeiro investimento despendido pela PETROBRAS no referido Polo Naval Offshore do Rio Grande foi a encomenda da plataforma P-53, que se constituiu na maior e mais moderna plataforma do tipo $\mathrm{FPU}^{6}$ da empresa. A construção ficou a cargo do Consórcio Quip S.A., formado pelas empresas Queiroz Galvão, ULTRATEC e IESA, e entregue no ano de 2008.

Porém, no ano de 2008, novos pedidos de expansão encabeçados pelo Estaleiro Rio Grande, grupo Wilson \& Sons e Consórcio Quip S.A, modificaram novamente as bases do Polo Naval e Offshore do Rio Grande. O estaleiro Rio Grande encaminhou duas propostas, a tornar o dique seco em um centro de construção em série de cascos de plataformas da classe $\mathrm{FPSO}^{7}$, e a montagem de plataformas das classes semi-subversível e monocoluna. Considerando tais transformações, o dique seco requer uma expansão dos iniciais 140 metros para 350 metros de extensão.

Esta proposta foi induzida pelo Governo Federal e pela PETROBRAS, dada a importância do empreendimento para o avanço socioeconômico do país. A fábrica de cascos será a primeira no mundo na produção em série de cascos para plataformas do tipo FPSO. Na sequência, o Estaleiro Rio Grande estipula um aumento na capacidade de processamento de aço, que inicialmente girava em torno de 1,5 mil toneladas/mês para um patamar de 5 a 6 mil toneladas/mês. Com esta proposta, este estaleiro estará apto não somente a suprir a demanda de chapas para a fabricação dos cascos das plataformas FPSO, mas também às demandas de chapas para navios que possivelmente ocorrerão via encomenda da TRANSPETRO para os futuros navios sonda. A seguir, o grupo Wilson \& Sons apresentou a terceira proposta no tocante à construção de embarcações de apoio marítimo em geral e também offshore. A última proposta é a do Consórcio Quip S.A. para

6 Floating Production Unit, ou Unidade de Produção Flutuante.

7 Floating Production, Storage and Off-Loading Platafform, ou Plataforma Flutuante de Produção, Armazenamento e Escoamento. 
a construção de um cais de 500 metros onde farão a montagem de módulos e blocos, tanto em plataformas offshore como em navios.

Assim, como já mencionado, as propostas modificam mais uma vez a estrutura do Polo Naval Offshore do Rio Grande, passando então a configurar um Polo Naval e Offshore (DOMINGUES et al., 2008). Importante ressaltar a profundidade que esta modificação traz, já que um Polo Naval e Offshore possibilita a construção de embarcações de apoio marítimo, navios e plataformas, atraindo ainda mais os atores situados a montante da indústria naval, como a indústria metalmecânica, química, eletroeletrônica, mobiliário, dentre outras. Um Polo Naval e Offshore configura-se em um espaço de produção integrando diferentes espaços de produção articulados.

Considerando o breve histórico apresentado acima, no qual foram abordados os projetos que deram inicio a implantação do polo naval e offshore no município do Rio Grande, bem como seus desdobramentos e, destacando as ações do Governo Federal e da PETROBRAS em consolidar a indústria naval no município e a interdependência desta indústria em relação aos demais segmentos da economia, podemos caracterizá-la como uma indústria motriz e, desta forma, enquadrar a implantação da indústria naval no município do Rio Grande como uma estratégia de desenvolvimento regional exógeno, baseado na teoria de Polos de Crescimento formulada pelo economista François Perroux.

Segundo Barquero (2002), esta estratégia de desenvolvimento regional exógeno foi largamente utilizada no Brasil nas décadas de 60 e 70, e tinha como elemento instigador a premissa de que regiões com desenvolvimento mais retardado pudessem promovê-lo através da adoção de medidas de desenvolvimento exógeno. Deste modo, uma parte do crescimento global da economia nacional seria dirigido para as regiões periféricas.

Ainda de acordo com o autor, a atração dos investimentos externos deu-se, sobretudo, através de subvenções e auxílios, incentivos à implantação, investimentos públicos em infraestrutura e, inclusive, mediante investimentos diretos realizados por empresas públicas, sendo que a ideia era formar polos de crescimento, que estimulariam a expansão das regiões mais atrasadas e, para tal fim, entraria em cena a indústria motriz.

Ao considerarmos a afirmação de Piccoli (2009), de que a indústria naval é formada por uma rede de suprimento que conta com mais de mil empresas de diversos segmentos da economia, além de possuir alto conteúdo tecnológico, e da mesma forma atentarmos para ação do Estado em implantar um polo naval e offshore no município do Rio Grande visando o fomento industrial na região, aliado ao fato da PETROBRAS ser até o momento a única cliente da referida indústria nascente, temos o claro demonstrativo da União agindo através de sua estatal PETROBRAS na tentativa de tirar do ostracismo econômico a região sul do Estado.

De posse destas informações, deve-se ter cautela ao analisar em como se dará a geração de desenvolvimento no COREDE Sul, pois ao se tratar de uma estratégia exógena, em que os atores impulsionadores, a indústria motriz, são de fora do COREDE, 
afere-se que uma das maneiras eficientes de o território se engajar nesta ação seria a atuação de empresas locais como fornecedoras à indústria motriz. Porém, relevante relatar que o estado do Rio Grande do Sul já possui locais extremamente concentrados dos segmentos industriais afins à indústria naval, estando esses locais fora do COREDE Sul.

Assim, buscar saber em que medida os atores regionais localizados no COREDE Sul irão participar deste novo ciclo de crescimento econômico induzido exogenamente, é algo que se impõe, bem como se tal inserção ficará restrita às demais regiões do estado do Rio Grande do Sul, onde se verifica a presença de potenciais fornecedores a esta nova cadeia produtiva.

Esta observação se faz pertinente, pois a teoria dos polos prega que a dinâmica de crescimento não se dá de forma igualitária na região, e sim de forma heterogênea, manifestando-se, ainda segundo Perroux (1995) apud Cavalcanti (2007), em polos ou pontos de crescimento, com intensidades variadas, expandindo-se por canais e com efeitos finais variáveis sobre toda a economia.

Barquero (2002) também cita que muitas vezes as políticas de desenvolvimento exógeno não alcançam os objetivos benéficos previstos à região, como segue.

Políticas de desenvolvimento exógeno nem sempre atingem seu objetivo de gerar processos de desenvolvimento econômico auto-sustentado, na medida em que o impulso inicial sofre "vazamentos", reduzindo assim a capacidade difusora dos investimentos externos, levando então a um desenvolvimento malsucedido em regiões atrasadas, muito em função do não aproveitamento do potencial local de crescimento, ocorrendo a exportação dos recursos as áreas mais desenvolvidas (BARQUERO, 2002, p. 184).

Portanto, com a decisão do Governo Federal em implantar o polo naval no município do Rio Grande, estabelece-se o segundo ciclo exógeno de desenvolvimento vivenciado pelo município, reproduzindo um modelo espacial de produção industrial explicitado na teoria dos polos de crescimento, qualificando a indústria naval como uma indústria motriz.

Neste sentido, os primeiros impactos econômicos, advindos da ação de um ator sintagmático, neste caso, o Estado Brasileiro, quando da decisão de implantar um polo naval no COREDE Sul já estão sendo sentidos pelo território, especialmente nos municípios do Rio Grande e Pelotas, como apresentados a seguir.

O COREDE Sul é formado por vinte e dois municípios, registrando uma participação de $13 \%$ do PIB estadual no ano de 2010. Do total do PIB do COREDE para este ano, cerca de $35 \%$ é formado pelo setor industrial, e $50 \%$ pelos setores de serviço e comércio, ressaltando que o eixo Pelotas-Rio Grande se destaca na formação da riqueza advinda desses dois últimos setores (FEIJO et al., 2010).

Atentando-se para estes dois municípios, segundo Madono (2010), Rio Grande está se consolidando como polo industrial regional, enquanto o município de Pelotas se consolida como polo de serviços do COREDE Sul. 
Os primeiros impactos econômicos advindos da implantação do polo naval já começam a ser observados, uma vez que houve um aumento no PIB de todos os municípios do COREDE Sul, com destaque para Rio Grande e Pelotas, que praticamente triplicaram seu PIB nos cinco anos que vão de 2005 a 2010. Rio Grande e Pelotas, em 2005, contabilizam um Produto Interno Bruto de $\mathrm{R} \$ 3.015 .265$ e $\mathrm{R} \$$ 2.629.072, respectivamente. Já no ano de 2010, Rio Grande obteve um PIB de R\$ 7.737.855 e, Pelotas R\$ 4.564.464 (FEE, 2012).

O ano de 2005 remonta ao início das tratativas para a implantação dos projetos voltados ao polo naval e offshore do Rio Grande. Em 2006, o estaleiro Rio Grande venceu a licitação para a construção do dique seco e no ano de 2007 a PETROBRAS realizou seu primeiro investimento no polo naval e offshore do Rio Grande, com a encomenda da plataforma P-53. Em 2008 a plataforma foi entregue à PETROBRAS e, em seguida ocorreram novos pedidos de expansão do Polo Naval, encabeçados pelo estaleiro Rio Grande, grupo Wilson \& Sons e Consórcio Quip S.A.

Com isso, o município do Rio Grande, neste espaço de tempo, tornou-se o quarto município mais rico do Rio Grande do Sul, refletindo claramente os novos investimentos ancorados no município.

\section{A POLÍTICA DE CONTEÚdO LOCAL E A CADEIA PRODUTIVA POTENCIAL SUPRIDORA DA INDÚSTRIA DO PETRÓLEO, GÁS NATURAL E NAVAL: O CASO DO RIO GRANDE DO SUL}

Até o presente momento a retomada da indústria naval brasileira está principalmente voltada para à indústria do petróleo e gás, atendendo quase que sumariamente encomendas da PETROBRAS. Considerando, como já citando anteriormente, a estagnação em que se encontravam estaleiros e fornecedores nacionais da indústria naval, destacam-se, a partir da primeira década deste século, duas iniciativas propostas pela Agência Nacional do Petróleo (ANP) e pela PETROBRAS que, aliadas à descentralização dos estaleiros no país, podem significar um forte aumento de demanda nos próximos anos para a indústria local de bens e serviços e, claramente favorecendo o surgimento de rede de fornecedores locais.

A primeira delas refere-se a uma retomada por parte da PETROBRAS em requerer um mínimo de conteúdo local em seus novos projetos. Neste sentido, a Companhia reserva aos estaleiros locais a preferência nas encomendas de navios e equipamentos para a exploração e produção de petróleo. Seguindo a mesma linha de incentivos, a ANP estipulou que as concessionárias devem assegurar a preferência à contratação de fornecedores brasileiros sempre que suas ofertas apresentem condições de preço, prazo e qualidade equivalentes às de outros fornecedores convidados a apresentar propostas (ANP, 2011).

Atentando-nos aos fornecedores de bens e serviços, tem-se que, segundo Britto (2008), a indústria da construção naval é uma indústria de montagem de bens de capital e 
necessita do fornecimento de um grande número de peças e equipamentos, os quais podem ser incluídos na classificação genérica de "navipeças".

As navipeças estão entre as metas das políticas industriais voltadas ao setor naval e elaboradas pelo Ministério do Desenvolvimento, Indústria e Comércio Exterior, o qual propõe o aumento do fornecimento das indústrias locais para até $85 \%$, com a utilização de navipeças nacionais nas embarcações (MACEDO, 2010).

As navipeças são extremamente importantes para a cadeia naval, pois respondem por uma grande parte dos custos de construção de uma embarcação. Segundo Picolli (2009), os estaleiros brasileiros nos últimos anos desembolsaram cerca de 450 milhões de reais, sendo que destes, entre $65 \%$ a $75 \%$ foram na compra de componentes.

Um estudo realizado pela BALance no ano de 2000 e apontado por Picolli (2009), apresentou a percentagem de utilização das principais demandas na construção de navios e plataformas, sendo eles distribuídos da seguinte forma: Tubulações e aços - 29\% para plataformas e $26 \%$ em embarcações de apoio; Sistemas de propulsão e energia - $15 \%$ nas plataformas e $20 \%$ embarcações de apoio; Elétrica, eletrônica e automação, equipamentos auxiliares (motores, bombas, compressores entre outros) operação geral, pintura e manuseio de carga - $11 \%$ a 15\%; Acomodações - 4\% a $8 \%$.

Analisando-se os dados citados no parágrafo anterior, tem-se clara a maior participação do segmento metalmecânico, seguido do segmento eletroeletrônico, na construção de embarcações offshore. Com isso, levando em conta a crise que acometeu o setor naval, acarretando o quase total desmantelamento de fornecedores que atuavam especificamente no suprimento naval, abre-se novamente a possibilidade da utilização das capacitações adquiridas por outros setores, como exemplo da cadeia automobilística, para o suprimento a indústria naval.

Setores que compõem os segmentos metalmecânico, eletroeletrônico, químico e moveleiro podem readaptar suas linhas de produção utilizando o know-how já adquirido ao longo de suas atuações. Neste sentido, o estado do Rio Grande do Sul apresenta grande vantagem, já que conta com consolidado segmento metalmecânico e eletroeletrônico extremamente competitivo.

De acordo com o SINAVAL (2011), os três principais polos da construção naval brasileira, considerando a tonelagem construída e emprego direto gerado, estão no Rio de Janeiro, Pernambuco e no Rio Grande do Sul.

Atentando para as características industriais do Rio Grande do Sul, tem-se que o Estado é o terceiro do País em número de estabelecimentos industriais. Estima-se que mais de $52 \%$ da atividade industrial gaúcha esteja concentrada na Região Metropolitana de Porto Alegre, sendo a indústria da transformação a que representa maior parte do valor adicionado bruto entre as indústrias do Estado (FIERGS, 2010).

Segundo Coester (2011), no Rio Grande do Sul está formado o segundo maior polo metalmecânico do país e o Estado ocupa a destacada segunda posição nacional também no ranking da concentração de indústrias eletroeletrônicas e de máquinas. 
Levando em conta todas as informações apontadas até o momento e a excelência do diversificado parque industrial do Rio Grande do Sul, com destaque para os segmentos metalmecânico, eletroeletrônico, químico e moveleiro concentrados nos COREDES Metropolitano, Vale do Rio dos Sinos, Serra, Produção e Norte, pode-se dizer que o Estado tem potencial de atuar como um grande polo supridor regional ao Polo Naval e Offshore do Rio Grande.

\subsection{Potencial de Suprimento à Indústria do Petróleo, Gás e Naval no Rio Grande do Sul: análise por COREDES}

Neste espaço realiza-se um primeiro desenho locacional no que se refere à potencial cadeia de fornecedores a IPG\&N no Rio Grande do Sul. Foram apontadas as empresas que já forneceram ao polo naval e offshore do Rio Grande na oportunidade da construção da plataforma P-53, através de terceirização ou da contratação direta pela QUIP S/A, bem como foram identificadas e tipificadas as empresas consideradas potenciais fornecedoras ao polo naval e offshore do Rio Grande, apuradas pela base de dados da Rede Petro/RS e pelo Projeto Adensamento da Cadeia Produtiva do Petróleo, Gás e Energia, promovido pelo SEBRAE/RS.

Desta forma, as empresas foram divididas de acordo com sua localização geográfica, sendo utilizado como recorte espacial os COREDES Metropolitano, Vale do Rio dos Sinos, Serra, Noroeste Colonial, Vale do Rio Pardo, Alto Jacuí, Central, Jacuí Centro, Centro-Sul, Produção, Norte e Fronteira Noroeste.

Dentre as vinte empresas que já forneceram ao polo naval e offshore do Rio Grande, quinze empresas foram terceirizadas para a montagem da plataforma P-53. Destas, treze são prestadoras de serviços e duas indústrias, sendo onze empresas pertencentes ao COREDE Metropolitano, o de maior participação em todos os COREDES analisados.

O número de empresas contratadas diretamente pela QUIP S/A, na região dos doze COREDES apurados, foram cinco, sendo todas prestadoras de serviços. Três destas empresas estão locadas na região do COREDE Metropolitano, que novamente sobressai entre os COREDES, com maior número de empresas contratadas pela QUIP S/A.

Com isso, destaca-se o COREDE Metropolitano com maior participação nos dois eixos analisados - terceirizadas para a montagem da plataforma P-53 e contratadas pela QUIP S/A.

No tocante às empresas consideradas potenciais fornecedoras ao polo naval e offshore do Rio Grande, foram mapeadas trezentas e cinco empresas nos doze COREDES considerados. Destas, cento e vinte e uma são micro e pequenas empresas (MPE's) participantes do Projeto de Adensamento da Cadeia Produtiva do Petróleo, Gás e Energia promovido pelo SEBRAE e, cento e oitenta e quatro empresas estão cadastradas na Rede Petro/RS. 
Atentando às micro e pequenas empresas participantes do projeto de capacitação promovido pelo SEBRAE, tem-se trinta e seis localizadas no COREDE Metropolitano, vinte e quatro no COREDE Vale do Rio dos Sinos e sessenta no COREDE Serra. Destaca-se, em todos os COREDES apontados, a maior participação de empresas do segmento metalmecânico, perfazendo um total de noventa e três, seguido do segmento eletroeletrônico, totalizando vinte empresas. O segmento de menor participação é o químico, com sete empresas participantes.

O COREDE Serra foi o que teve maior participação, totalizando sessenta MPE's, e destas cinquenta e uma estão no segmento metalmecânico.

Já as empresas levantadas através do cadastro da Rede Petro/RS, estas somam cento e oitenta e quatro, sendo oitenta e oito localizadas no COREDE Metropolitano, quarenta e nove no COREDE Vale do Rio dos Sinos, trinta e uma no COREDE Serra e, por fim, dezesseis empresas situadas nos demais nove COREDES analisados.

Entre os segmentos levados em conta para esta análise, destaca-se novamente o metalmecânico, com cento e dez empresas participantes, seguido pelo segmento eletroeletrônico com cinquenta e nove empresas e, em menor número, o segmento químico, com quinze empresas cadastradas.

O COREDE Metropolitano foi o que teve maior participação, totalizando oitenta e oito empresas, e destas, quarenta e oito estão no segmento metalmecânico.

Destaca-se ainda que, em todos os COREDES, o segmento metalmecânico apresentou o maior número de empresas, corroborando a tradição do Estado neste segmento.

No entanto, ao considerarmos os COREDES citados acima, a questão que se põe é se o COREDE Sul, sede do referido polo, também será inserido nesta cadeia de suprimento, já que a carteira de encomendas dos estaleiros instalados no mesmo apresenta grande volume de projetos, ou se servirá tão somente de sede destas indústrias.

\section{DESAFIOS COLOCADOS AO COREDE SUL}

De acordo com Ferraz et al., (2002), o mercado de equipamentos para exploração e produção de petróleo offshore está numa fase de pico de encomendas. A produção de petróleo em águas profundas e ultraprofundas torna o estoque de equipamentos existente obsoleto para as novas exigências tecnológicas, representadas por lâmina d'água superior a 1.000 metros de profundidade.

Esta nova fase na exploração do petróleo brasileiro trouxe a reboque um novo desenho locacional desta indústria no país, materializada principalmente pela nova espacialização dos estaleiros, fato este já comentado anteriormente. Com isso, se torna extremamente oportuno estudarmos os primeiros passos de uma cadeia de fornecedores locais que poderá ou não se estruturar em regiões até então consideradas estagnadas e sem histórico da indústria em questão, caso do COREDE Sul. 
Como já citado anteriormente, o polo naval e offshore do Rio Grande foi implantado no Porto do Rio Grande através de uma estratégia do Governo Federal em descentralizar a indústria naval fortemente concentrada na região Sudeste do país e, por este Porto apresentar as dimensões físicas necessárias a este tipo de empreendimento.

Atualmente no COREDE Sul, no Porto do Rio Grande, estão em operação dois estaleiros, Engevix/Ecovix e Quip S/A No município vizinho, São José do Norte, esta sendo construído o estaleiro EBR, planejado para a montagem de plataformas marítimas e construção de embarcações de apoio à exploração de petróleo. Todos estes empreendimentos configuram-se em oportunidade de suprimento tanto para fornecedores internacionais, quanto para os nacionais. Contudo, há uma grande vantagem quando existe um parque supridor localizado junto aos estaleiros, pois, de acordo com Favarin et. al., (2008), esta concentração é fator determinante de competitividade, a exemplo do que se verifica no continente europeu, onde alguns estaleiros somente puderam sobreviver com as possibilidades de aglomeração e cooperação entre firmas.

O polo naval e offshore do Rio Grande apresenta dupla excentricidade em relação à cadeia de fornecimento do mesmo. Primeiramente, a distância do parque produtivo do estado do Rio Grande do Sul, concentrado especialmente nos COREDES Metropolitano, Vale do Rio dos Sinos, Serra e Produção, fato já debatido no presente trabalho e, a segunda excentricidade, referindo-se a extrema distância do Polo aos fornecedores localizados no centro do país.

Este cenário, de certa forma, beneficiaria fornecedores localizados no COREDE Sul, portanto, a questão que se põe é se empresas localizadas no mesmo irão participar desta cadeia de suprimento. Esta primeira questão é tomada pela incerteza, dada a pouca existência de indústrias ligadas aos segmentos metalmecânico, químico e eletroeletrônico no COREDE Sul, ou então se as mesmas irão apenas atuar no fornecimento de produtos e serviços de baixo valor agregado, repassando a maior parte do montante do suprimento a outras regiões do Estado, bem como do país, neste caso com a logística dando suporte a ação.

Uma análise do perfil das empresas atuantes no COREDE Sul, e sua funcionalidade enquanto atendendo demandas de produção do polo naval e offshore de Rio Grande, é feita a seguir.

Focando então nas empresas atuantes no COREDE Sul terceirizadas para a construção da plataforma P-53, foram identificadas vinte e oito empresas, sendo todas prestadoras de serviços.

As empresas contratadas diretamente pela Quip S/A, para a construção da plataforma P-53, somam dez e, novamente são prestadoras de serviços.

Em uma análise preliminar, chega-se à constatação de que no COREDE Sul houve a maior inserção empresarial em comparação aos demais COREDE's. Porém, ao analisar mais de perto esta questão, aprofundando o debate sobre a tipologia de serviço ou produtos ofertados, tem-se que, num primeiro momento, a inserção de empresas do 
COREDE Sul se deu exclusivamente através de prestadoras de serviços, seguindo em parte a tendência do Rio Grande do Sul naquele primeiro momento.

No tocante às empresas consideradas potenciais fornecedoras ao polo naval e offshore do Rio Grande, foram identificadas trinta e duas empresas nos três segmentos analisados (metalmecânica, química e eletroeletrônica). Destas, vinte e oito são micro e pequenas empresas participantes do Projeto de Adensamento da Cadeia Produtiva do Petróleo, Gás e Energia promovido pelo SEBRAE e, quatro empresas estão cadastradas na Rede Petro/RS.

Atentando às micro e pequenas empresas participantes do projeto de capacitação promovido pelo SEBRAE, no segmento metalmecânico foram identificadas dezesseis empresas. Ressaltamos que entres estas, apenas uma é fabricante de equipamentos, e as demais são prestadoras de serviços e comércio. Para o segmento eletroeletrônico foram apuradas dez empresas, e destas, destaca-se uma empresa de automação industrial e outra de tecnologia de informação. E no segmento químico foram identificadas duas empresas, uma distribuidora de lubrificantes e aditivos e outra de comércio de tintas, porém nenhuma indústria no segmento.

Das empresas levantadas através do cadastro da Rede Petro/RS, apenas quatro ${ }^{8}$ situadas no COREDE Sul estão enquadradas nos segmentos analisados pelo presente trabalho, demonstrando o baixo nível de mobilização e/ou inserção deste COREDE na dinâmica e competitiva rede que forma à cadeia do petróleo e gás natural.

Após esta apresentação, pode-se inferir que a resposta dos atores locais na constituição da cadeia de fornecedores para o polo naval e offshore não esta sendo significativa. Elenca-se, neste contexto, como fatores responsáveis por este fato a já citada pouca existência de indústrias ligadas aos setores de metalmecânica, química e eletroeletrônica, bem como a estagnação econômica em que se encontrava o referido COREDE no período de 1980 a 2000, que inviabilizou uma resposta rápida à demanda de produção industrial surgida pelo polo naval e offshore do Rio Grande.

Desta forma, levando em conta a quase inexistência das cadeias produtivas dos segmentos da metalmecânica, eletroeletrônica e química no COREDE Sul e, a pequena participação de empresas sediadas no COREDE Sul, muitas das quais prestadoras de serviços de baixo valor agregado, conclui-se que a resposta deste COREDE tende a ser demasiadamente menor em comparação aos demais COREDES apontados pelo presente trabalho.

8 No total na base de dados da Rede Petro/RS foram identificadas cinco empresas do COREDE Sul, sendo está última responsável por transportes marítimos, portanto não se enquadrando nos segmentos alvo deste estudo. 


\section{ANÁLISE DE CONCENTRAÇÃO: O ÍNDICE HIRSCHMAN - HERFINDAHL (HH) PARA OS COREDES COM MAIOR NÚMERO DE EMPREGADOS}

Para a análise do índice de concentração Hirschman-Herfindahl (HH), utiliza-se a seguinte fórmula proposta por Hoffman (2008).

$$
H H=\varepsilon_{i=1 Y_{i}^{2}}^{n} H H=\varepsilon_{i=1 Y_{i}^{2}}^{n} \text {, em que: } y=\frac{x_{i}}{\varepsilon_{i=1 x_{i}}^{n}}
$$

Como observado na fórmula acima, o índice HH é uma medida estatística de concentração, calculada a partir da soma dos quadrados do setor em análise em relação ao domínio total. De acordo com esse índice, é considerado desconcentrado o setor ou área com índice até 1.000 , moderadamente concentrado entre 1.000 e 1.800 e extremamente concentrado acima de 1.800. Para tanto, foram utilizados os dados da Relação Anual de Informação Social (RAIS).

O Índice HH é utilizado para demonstrar o grau de concentração de uma área ou setor, sendo calculado pela soma dos quadrados das parcelas de participação de cada atividade econômica em relação ao total. No presente estudo, utilizam-se dados de emprego para calcular o $\mathrm{HH}$.

A tabela 1 apresenta os Índices Hirschman-Herfindahl (HH), bem como as variações percentuais, elaborados com base no número de empregados dos anos de 2002 a 2013, dos COREDES que apresentam maior representatividade no número de empregados no Rio Grande do Sul.

TABELA 1 - Índices Hirschman-Herfindahl (HH) dos COREDES com Maior Número de Empregados nos anos de 2002 a 2013.

\begin{tabular}{|c|c|c|c|c|c|c|c|c|}
\hline \multirow[t]{2}{*}{ ANO } & \multicolumn{8}{|c|}{ COREDES } \\
\hline & Sul & Central & $\begin{array}{l}\text { Front. } \\
\text { Oeste }\end{array}$ & $\begin{array}{l}\text { Metrop. } \\
\text { Delta do } \\
\text { Jacuí }\end{array}$ & Produção & Serra & $\begin{array}{l}\text { Vale do } \\
\text { Rio dos } \\
\text { Sinos }\end{array}$ & $\begin{array}{l}\text { Vale do } \\
\text { Taquari }\end{array}$ \\
\hline 2002 & $1.338,01$ & $1.504,80$ & $1.635,64$ & $1.550,30$ & $1.539,05$ & $2.911,75$ & $2.689,88$ & $3.117,41$ \\
\hline 2003 & $1.382,53$ & $1.518,98$ & $1.611,11$ & $1.595,11$ & $1.597,00$ & $2.973,17$ & $2.558,99$ & $3.120,71$ \\
\hline 2004 & $1.372,59$ & $1.557,14$ & $1.655,26$ & $1.543,49$ & $1.617,44$ & $3.080,20$ & $2.552,47$ & $3.168,49$ \\
\hline 2005 & $1.351,77$ & $1.615,49$ & $1.631,19$ & $1.520,44$ & $1.584,53$ & $2.950,62$ & $2.419,54$ & $3.007,95$ \\
\hline 2006 & $1.362,31$ & $1.622,57$ & $1.607,48$ & $1.190,89$ & $1.568,59$ & $2.931,57$ & $2.393,70$ & $2.985,68$ \\
\hline 2007 & $1.367,39$ & $1.627,92$ & $1.650,89$ & $1.438,26$ & $1.575,28$ & $2.973,37$ & $2.339,80$ & $2.836,54$ \\
\hline 2008 & $1.271,82$ & $1.606,02$ & $1.635,08$ & $1.427,60$ & $1.562,31$ & $2.950,52$ & $2.200,27$ & $2.696,22$ \\
\hline 2009 & $1.290,92$ & $1.611,70$ & $1.666,20$ & $1.430,72$ & $1.515,04$ & $2.786,56$ & $2.139,55$ & $2.561,35$ \\
\hline 2010 & $1.310,76$ & $1.569,95$ & $1.633,04$ & $1.400,43$ & $1.517,71$ & $2.859,50$ & $2.088,61$ & $2.464,86$ \\
\hline 2011 & $1.284,59$ & $1.611,78$ & $1.662,20$ & $1.373,95$ & $1.506,90$ & $2.797,91$ & $2.006,05$ & $2.448,68$ \\
\hline 2012 & $1.268,26$ & $1.610,34$ & $1.661,13$ & $1.378,04$ & $1.534,01$ & $2.664,15$ & $1.939,71$ & $2.386,77$ \\
\hline 2013 & $1.265,08$ & $1.607,33$ & $1.684,76$ & $1.348,27$ & $1.492,98$ & $2.618,37$ & $1.885,36$ & $2.325,81$ \\
\hline $\begin{array}{l}\text { Variação } \\
\text { \% HH }\end{array}$ & $-7,14 \%$ & $-5,97 \%$ & $4,81 \%$ & $13,22 \%$ & $-4,82 \%$ & $-10,68 \%$ & $-21,24 \%$ & $-22,10 \%$ \\
\hline
\end{tabular}

Fonte: Resultados da pesquisa 
De acordo com a tabela acima, e levando em conta, que se considera desconcentrado o setor ou área com índice $\mathrm{HH}$ até 1.000, moderadamente concentrado entre 1.000 e 1.800 e extremamente concentrado acima de 1.800 , temos que os COREDES Sul, Central, Fronteira Oeste, Metropolitano Delta do Jacuí e Produção apresentam índices moderados de concentração, já os COREDES Serra, Vale do Rio dos Sinos e Vale do Taquari apresentam índices extremamente concentrados.

Os COREDES, que de acordo com a classificação proposta acima, apresentaram índices de extrema concentração, contam com maiores valores de HH no setor industrial, mas especificamente indústrias de transformação.

Ainda de acordo com a tabela 1, observa-se em todo o período analisado, que os índices HH do COREDE Vale do Rio dos Sinos apresentam diminuições contínuas, diferentemente do COREDE Serra, que apresenta oscilações nos anos.

Percebe-se também, que estes foram os COREDES que registraram maiores variações negativas, ou seja, ao longo dos doze anos apontados tiveram maiores quedas nos índices HH.

O COREDE Vale do Taquari teve uma variação de -22,10\%, o COREDE Vale do Rio dos Sinos $-21,24 \%$ e o Serra $-10,68 \%$. Neste sentido, com base nos dados utilizados, se torna possível verificar que o COREDE Vale do Rio dos Sinos foi o único que apresentou queda continua nos índices HH do setor industrial, os demais oscilaram seus valores. Contudo, pode-se afirmar que em todos os casos, a participação do setor de serviços tem evoluído paulatinamente.

Os COREDES que apresentaram índices moderados de concentração têm como principal característica valores maiores de $\mathrm{HH}$ no setor de serviços, especialmente comércio, reparação de veículos automotores, objetos pessoais e domésticos, administração pública, defesa e seguridade social. Importante salientar que o COREDE Produção, durante os anos de 2002 a 2006, apresentou maiores índices HH no setor industrial, porém, a partir do ano de 2007, houve uma evolução nos índices ligados ao setor de serviços, passando este a concentrar maior número de trabalhadores.

Por meio da tabela 1, é possível observar também que dois COREDES apresentam variações positivas nos índices HH, Fronteira Oeste (4,81\%) e Metropolitano Delta do Jacuí (13,22\%). O COREDE Metropolitano Delta do Jacuí oscilou principalmente entre duas áreas do setor de serviços - administração pública, defesa e seguridade social e educação. Já o COREDE Fronteira Oeste, nos doze anos apontados, apresenta maiores índices na área de administração pública e no setor de agricultura.

Dentre os que tiveram variações negativas destacamos o COREDE Sul, que frente aos demais apontados na tabela 1, apresenta os menores índices para todo o período. Esta tendência se acentua no decorrer dos anos. Nota-se que, a partir do ano de 2008 o índice diminui (1.271,82), apresentando duas elevações nos anos de 2009 (1.290,92) e 2010 $(1.310,76)$, retornando a diminuir no ano de $2011(1.284,59)$ chegando ao menor valor no ano de $2013(1.265,08)$, conforme demonstra o gráfico 1. 


\section{GRÁFICO 1 - Evolução dos Índices Hirschman-Herfindahl (HH) nos COREDES com Maior Número de Empregados no Rio Grande do Sul nos anos de 2002 a 2013.}

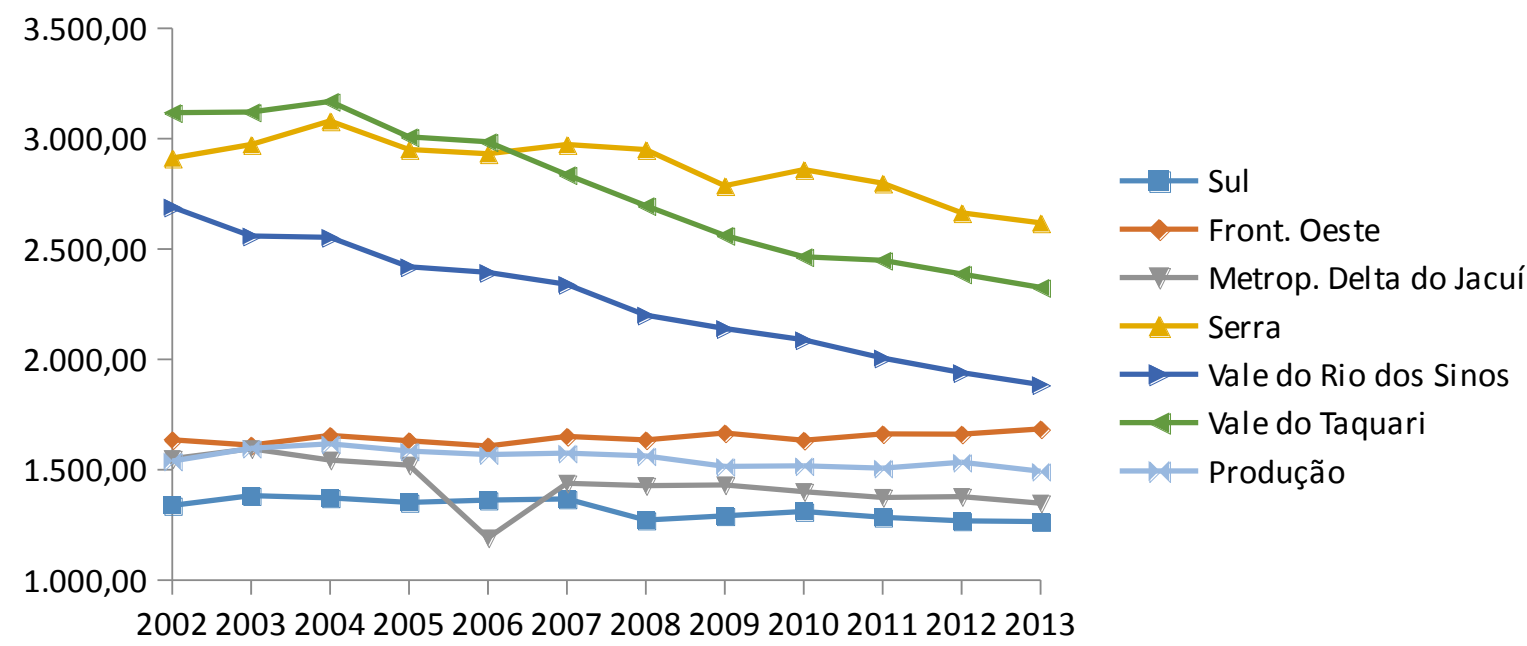

Fonte: Elaboração própria

Atentando-nos aos fatos ocorridos entre os anos apontados acima, temos que a partir do ano de 2003, segundo Pires, Gomide e Amaral (2014), são implantadas as chamadas "iniciativas de revitalização da indústria naval" as quais impactam fortemente o Estado do Rio Grande do Sul e, em especial o COREDE Sul, sede do Polo Naval e Offshore do Rio Grande. Com isso, o ano de 2005 remonta ao início das tratativas para a implantação dos projetos voltados ao polo naval e offshore do Rio Grande. Em 2006, o estaleiro Rio Grande venceu a licitação para a construção do dique seco e no ano de 2007 a PETROBRAS realizou seu primeiro investimento no polo naval e offshore do Rio Grande, com a encomenda da plataforma P-53. Em 2008, a plataforma foi entregue à PETROBRAS e, em seguida ocorreram novos pedidos de expansão do Polo Naval, encabeçados pelo estaleiro Rio Grande e Consórcio Quip S.A.

Nesse sentido, o Polo Naval e Offshore do Rio Grande, desde 2007, ano do primeiro investimento no polo atraiu empreendimentos, principalmente no setor de serviços, fato discutido na seção anterior. Dessa forma, podemos especular que a implantação deste empreendimento ajudou a acentuar uma tendência já existente no COREDE, seja ela a desconcentração de suas atividades econômicas.

Logo, o que se pode observar é que dentre os COREDES com maior número de empregados, existem duas realidades, três COREDES com extrema concentração no setor industrial - Serra, Sinos e Taquari e, cinco COREDES apresentando concentração moderada - Sul, Fronteira Oeste, Metropolitano e Produção, especialmente nos setor de serviços.

Acredita-se que as atividades do polo naval e Offshore do Rio Grande tendam a aprofundar uma característica já predominante no COREDE Sul, a desconcentração. Isto 
justamente pelo fato do RS apresentar locais extremamente concentrados dos segmentos industriais afins a indústria naval, estando esses em local fora do COREDE Sul.

\section{CONCLUSÕES FINAIS}

Os principais objetivos do presente trabalho foram, primeiramente, identificar empresas fornecedoras à IPG\&N localizadas no Rio Grande do Sul e, em particular, na região do COREDE Sul, inseridas na Rede Petro/RS e SEBRAE (Serviço de Apoio às Micro e Pequenas Empresas), a fim de analisar em que dimensão estas empresas fornecedoras à IPG\&N estão constituídas dentro do COREDE Sul. Posteriormente realizou-se uma breve análise comparativa do grau de concentração das atividades econômicas entre os oito COREDES com maior número de empregados. Para tanto, utilizou-se do índice de concentração Hirschman-Herfindahl (HH). Neste sentido, deu-se atenção especial ao COREDE Sul observando se, ao longo dos anos, ocorreram alterações no grau de concentração de suas atividades pela operação do Polo Naval e Offshore.

O que se pode inicialmente apontar é que a primeira inserção de fornecimento para a construção da plataforma P-53 foi, em sua maioria, através de prestadoras de serviços. Neste aspecto seguiu a tendência do Estado, que também apresentou como primeira inserção de fornecimento à construção da plataforma P-53 um maior índice de prestadoras de serviços, e não deve ser analisada de forma tão negativa levando em conta o não preparo do COREDE Sul em atividades demandadas por esta indústria.

Contudo, visando justamente esta lacuna, foram criados projetos de capacitação por entidades com know-how para oferecer suporte e soluções para as empresas que realmente estão interessadas neste novo setor econômico. Porém, preocupa a baixa adesão de atores do COREDE Sul, por exemplo, ao cadastro Rede Petro/RS.

A atual fase de desenvolvimento que o COREDE Sul está vivenciando pode ser extremamente excludente caso as empresas localizadas nesse território não reajam a tão poderosos estímulos. Levando em conta a estagnação econômica em que se encontrava este COREDE, é extremamente importante e urgente a iniciativa dos atores locais no sentido de empreender empresarialmente, particularmente nas atividades industriais dos segmentos apontados neste estudo.

Neste sentido, no que tange ao COREDE Sul, observamos até o momento os atores locais situados à margem do empreendimento, ou seja, fornecendo serviços de menor valor agregado, e em áreas consideradas de serviço de apoio à indústria naval, e não efetivamente na construção de módulos e plataformas. O desafio real é o conteúdo tecnológico e as escalas de produção, variáveis estas que podem ser revertidas no tempo com a prática da inovação, a capacitação das empresas e o empreendedorismo.

Porém, tal desafio é palpável para a realidade tecno-produtiva presente nos COREDES Metropolitano, Vale do Rio dos Sinos e Serra, onde se constatou não só uma 
massiva presença de segmentos industriais potencias fornecedores a esta nova indústria, como a forte presença de instituições acadêmicas voltadas à transferência de conhecimento sob a forma da inovação tecnológica, articuladas a uma vocação cultural de empreendedorismo, aspectos estes não encontrados no COREDE Sul.

E quando ampliamos a análise, observando os índices de concentração das atividades econômicas do COREDE Sul, temos que o mesmo apresenta concentração moderada e maiores índices HH no setor de serviços. Estes índices, a partir do ano de 2007, caem ainda mais, caracterizando um aprofundamento maior de desconcentração. Logo, podemos inferir que as atividades do Polo Naval e Offshore do Rio Grande tendem a aprofundar uma característica já predominante no COREDE Sul, a desconcentração. Isto justamente pelo fato do RS apresentar locais extremamente concentrados dos segmentos industriais afins a indústria naval, estando esses em local fora do COREDE Sul.

Cabe ressaltar ainda, que o COREDE Sul está sendo fortemente impactado pela desestruturação do Polo Naval e Offshore do Rio Grande. Tal situação teve inicio em meados do ano de 2014 e alterou negativamente a dinâmica econômica dos municípios. Indicadores como emprego e renda sofreram bruscas alterações em curto espaço de tempo, com cerca de cinco mil trabalhadores demitidos somente no município de Rio Grande, ocorreu também o fechamento de inúmeras empresas fornecedoras ao Polo, além do encerramento das atividades de alguns estaleiros, sendo esses efeitos reflexos da suspensão de encomendas e não renovação de contratos por parte da PETROBRAS. Assim, tais evidências majoram a importância e a necessidade de incentivos advindos das políticas públicas para o desenvolvimento regional.

Superar estas desvantagens locacionais e encontrar novos mercados consumidores, eis os grandes desafios colocados ao território COREDE Sul, de ser agente protagonista de seu futuro, e não agente passivo frente a este processo de transformação produtiva, econômica e social.

\section{REFERÊNCIAS}

BARQUERO, A. V. Política de desenvolvimento local. In: Desenvolvimento endógeno em tempos de globalização. Porto Alegre, Ed. UFRGS, 2002. cap. 8.

BRASIL. Agência Nacional do Petróleo, Gás Natural e Biocombustíveis. Cláusulas de conteúdo local. Disponível em:

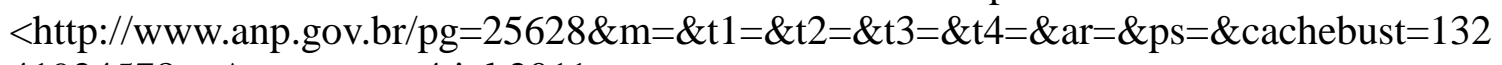
41924578>. Acesso em: 4 jul.2011.

BRASIL. Ministério do Desenvolvimento, Indústria e Comércio Exterior. Desenvolvimento de ações de apoio à cadeia produtiva da indústria da construção naval e Marinha Mercante. Relatório. Brasília, 2002. 22p. 
BRASIL. Ministério do Trabalho e Emprego. Relação Anual de Informações (RAIS). <http://portal.mte.gov.br/rais/> Acesso em 18 set. 2014.

BRITTO, J. Estudo da competitividade da indústria Brasileira de bens e serviços do setor de P\&G e o Setor de Navipeças. Relatório IEPROMINP. Rio de Janeiro, RJ, 2008, $26 \mathrm{P}$.

CATÁlogo FIERGS. Cadastro industrial do Rio Grande do Sul 2010. FIERGS, 2011. CD-ROM

CAVALCANTI, L. R. M. T. Produção Teórica em economia regional: uma proposta de sistematização. Revista ABER, Associação Brasileira de Estudos Regionais e Urbanos, 2007.

COESTER, M. Indústria oceânica (offshore) do Rio Grande do Sul. In: CAFÉ COM ENERGIA - ONIP. Rio de Janeiro, 2011. Disponível em: <http://www.onip.org.br/cafe23marcus_agdi.pdf>. Acesso em: 20 agos. 2011

DOMingueS, M. V. D. L. et al. Polo Naval do Rio Grande: Primeiros insights sobre a formação de um cluster portuário marítimo. In: IV Seminário Internacional sobre Desenvolvimento Regional, 4., 2008, Santa Cruz do Sul, Anais eletrônicos. p. 1-4.

EMPRESAS CADASTRADAS. In: Rede Petro/RS. Links. 2010. Disponível em: <http://www.redepetro.rs.gov.br/portal/index.php?menu=empresalista\&cod=6\&cat=1>. Acesso em: vários acessos.

FAVARIN, J. et al. Estratégias para a navipeças brasileira. In: Centro de Estudos e Gestão Naval. 2008. Disponível em: <www.gestaonaval.org.br/...\%20Navipeças/> Acesso em:17 dez. 2010

FEDERAÇÃO DAS INDÚSTRIAS DO ESTADO DO RIO GRANDE DO SUL. Panorama Econômico do Rio Grande do Sul 2010. Porto Alegre, 50 transparências. Disponível em: < www.fiergs.org.br/download.asp?arquivoCaminho=/files/.../>. Acesso em: 12 jan. 2011.

FEIJO, F. T. et al. Potencial de criação de empregos no Rio Grande do Sul com a implantação do polo naval de Rio Grande e concentração do emprego formal no COREDE Sul. In: $5^{\circ}$ Encontro de Economia Gaúcha, 5., 2010, Porto Alegre. Anais eletrônicos. Disponível em:〈http://www.pucrs.br/eventos/eeg/trabalhos/80.doc>. Acesso em 6 out. 2010.

FERRAZ. J. C; et al. Cadeia Produtiva da Indústria Naval. In: Estudo da competitividade de cadeias integradas no Brasil: impactos das zonas de livre comércio. Campinas, 2002, i, p. 1-48. 
FUNDAÇÃO DE ECONOMIA E ESTATÍSTICA. Resumo estatístico RS COREDE Sul. Disponível em:<http://www.fee.rs.gov.br/sitefee/pt/content/resumo/pg_coredes_detalhe.php?corede= Sul>. Acesso em: 10 mai 2013

HOFFMAN, R. Distribuição de Renda: Medidas de Desigualdade e Pobreza. São Paulo. Ed. USP, 1998.

MACEDO, C. Política industrial para o setor naval. In: II WORKSHOP REDE DE INOVAÇÃO PARA A COMPETITIVIDADE DA INDÚSTRIA NAVAL E OFFSHORE. Rio Grande: 2010. 10 transparências, color. Disponível em: <http://www.furg.br/workshopricino2010>. Acesso em: 26 nov. 2010.

MADONO, D. T. Potenciais impactos da implantação do polo naval do Rio Grande: uma análise sob a ótica da economia regional. 2010. Monografia- Instituto de Economia, Administração e Ciências Contábeis, Universidade Federal do Rio Grande, Rio Grande, 2010.

OLIVEIRA, A.; et.al. Polos supridores regionais: oportunidades, desafios e estratégias. Rio de Janeiro, 2010. 31 transparências, color.

PICOLLI, H. C. Diagnóstico da Cadeia Produtiva da metalmecânica para a indústria de construção naval do Rio Grande do Sul. In: Relatório FURG/SEDAI Desenvolvimento e consolidação do Polo Naval e Offshore de Rio Grande. Rio Grande, 2009. cap II.

PIRES, R. GOMIDE, A. AMARAL, L. A Ver Navios? A Revitalização da Indústria Naval no Brasil Democrático. In: Ressurgimento da Indústria Naval no Brasil (2000-2013). IPEA. Brasília, 2014, p. 109-150.

REDE PETRO RS. Objetivos da Rede. 2010. Disponível em: http://www.redepetro.rs.gov.br/portal/index.php?menu=texto\&cod=3\&id=7 Acesso em: 26 mai. 2010.

RIO GRANDE DO SUL (Estado). Secretária de Planejamento, Gestão e Participação Cidadã. COREDES. Disponível em: <http://www.scp.rs.gov.br/>. Acesso em: 16 set 2011.

SABBATINI, R. (Coord). Perspectivas do investimento em mecânica. Rio de Janeiro: UFRJ, Instituto de Economia, 2008/2009. 252p. Relatório integrante da pesquisa "Perspectivas do investimento no Brasil" em parceria com o Instituto de Economia da UNICAMP, financiada pelo BNDES. Disponível em: <http://www.projetopib.org/?p=documentos>. Acesso em 1 jun. 2010.

SERVIÇO DE APOIO À MICRO E PEQUENA EMPRESA. Quem Somos. 2010. Disponível em: $<$ http://www.sebrae.com.br/customizado/sebrae/institucional/quemsomos/>. Acesso em: 26 mai. 2010. 
SERVIÇO DE APOIO À MICRO E PEQUENA EMPRESA. Projeto Adensamento da Cadeia Produtiva do Petróleo, Gás e Energia 2009 - 2011: empresas participantes. 2010.

SFREDO, M. Empresas gaúchas disputam US\$ 22 bi em investimentos da PETROBRAS. Jornal Zero Hora, Porto Alegre, 22 jun. 2010. Caderno Economia, p 14.

SILVA, C. R. S; FURTADO, A. T. Uma análise da nova política de compras da PETROBRAS para seus empreendimentos offshore. Revista Gestão Industrial, Universidade Tecnológica Federal do Paraná, Ponta Grossa, 2006. Disponível em:

<http://www.pg.utfpr.edu.br/depog/periodicos/index.php/revistagi/.../104>. Acesso em: 30 jul. 2010.

SINDICATO NACIONAL DA INDÚSTRIA DA CONSTRUÇÃO NAVAL. Histórico resumido da indústria da construção naval no Brasil, 2010. Disponível em: <http://www.sinaval.org.br/balançohistoriaindustrianaval.pdf >. Acesso em: 20 mai. 2010.

SINDICATO NACIONAL DA INDÚSTRIA DA CONSTRUÇÃO NAVAL. Resultados da indústria da construção naval brasileira 2010, 2011. Disponível em <http://www.sinaval.org.br/SINAVAL-Resultados2010.pdf>. Acesso em 16 agost. 2011.

SINDICATO NACIONAL DA INDÚSTRIA DA CONSTRUÇÃO NAVAL. Carteira de Encomendas 2012, 2012. Disponível em <http://www.sinaval.org.br/docs/SINAVALCenario2012-4tri-CarteiraEncomendas.pdf>. Acesso em 20 mai. 2013.

TELLES, Pedro. Surgimento da grande construção naval mercante no Brasil. In: História da construção naval no Brasil. Fundação de Estudos do Mar, 2001. cap. V.

TRANSPETRO. Transporte marítimo - programa de navios, 2010. Disponível em: <http://www.transpetro.com.br/TranspetroSite/appmanager/transpPortal/transpInternet?_ $\mathrm{nfpb}=$ true\&_windowLabel=barraMenu_3\&_nffvid=\%2FTranspetroSite $\% 2$ Fportlets $\% 2 \mathrm{Fb}$ arraMenu\%2FbarraMenu.faces\&_pageLabel=pagina_base\&formConteudo:codigo=106>. Acesso em: 25 mai. de 2010.

VENTURA, M. O estudo de caso como modalidade de pesquisa. Revista SOCERJ, Rio de Janeiro, p. 383-386, set-out. 2007. 